Article

\title{
Increase in Robustness against Effects of Coil Misalignment on Electrical Parameters Using Magnetic Material Layer in Planar Coils of Wireless Power Transfer Transformer
}

\author{
Joao Victor Pinon Pereira Dias * and Masafumi Miyatake \\ School of Science and Technology, Sophia University, Tokyo 102-8554, Japan; miyatake@sophia.ac.jp \\ * Correspondence: victor@eagle.sophia.ac.jp; Tel.: +81-03-3238-3407
}

Received: 4 July 2018; Accepted: 23 July 2018; Published: 30 July 2018

\begin{abstract}
Utilization of wireless power transfer in light rail transits is seen as one solution for electrification of lines. The main advantage of this supply system is the reduction of installation; moreover, the alignment between the transmitter coil in the track and the receiver coil in the train should be perfect in order not to affect the power transfer. To reduce the effects of misalignment on the input and output electric parameters of the system, a new planar core and coil design, called hybrid intercore coil, is proposed. The proposed design uses a magnetic material layer between the windings in the inner half of the coil to create a non-uniform magnetic field distribution, which makes the system more robust against the effects of coil misalignment on the system current and voltage. Simulations with finite element method software were conducted to compare designs. The results show that the proposed design is less susceptible to the effects of misalignment and is more efficient. Prototype cores were constructed to verify the simulation results. Measurements show a smaller input overcurrent and output overvoltage when operating in resonance mode. The proposed design reduced the effects of coil misalignment on electrical parameters.
\end{abstract}

Keywords: misalignment; wireless power transfer; light rail transit; planar coil

\section{Introduction}

The adoption of clean energy sources has led to a reduction in the emission of greenhouse gases and will allow greener transportation. Most mass transport systems (e.g., subways and commuter trains) are powered by electricity, but automobiles powered by internal combustion engines are still dominant for personal transport.

To reduce the utilization of personal cars and buses in city centers, cities are installing light rail transit (LRT) systems [1]. Although LRT has been used since the initial use of electric traction in railways [2], lines have been removed in many cities to make more space for cars, buses, and trucks [3].

LRT uses a small train set that can run on a non-segregated track, where there is no separation between the road and the track, allowing various transportation systems to share the same space [4]. The fact that the system can be installed in the existing surroundings reduces construction cost and installation time compared to those for other mass transit solutions.

LRT is not only used in city centers. It can be used to connect the suburbs with a city center, especially where the quantity of passengers cannot sustain the operation of a commuter train or a subway [5]. LRT can also be used as a collector system for major commuter and subway lines [6].

Most LRT systems use electric power. Those that use diesel are primarily in rural areas with single non-electrified track lines [7]. Most examples of electric-powered LRT use catenary-pantograph systems [6], but trolley poles [8] and electrified third rails [9] are also used. 
In addition to environmental concerns regarding transportation, there are also visual pollution and safety concerns. Catenaries, trolley poles, and third rails, which are bare conductors used to supply power to LRT, create safety issues for passengers and other people nearby and are a form of visual pollution, especially at historical sites [10]. Various ideas have been proposed to eliminate these bare conductors and allow LRT to operate with minimal effects on the surroundings. The proposed solutions can be divided in two types, namely those that eliminate the bare conductors in part of the track and those that the contact wire is eliminated. For both types, an energy storage device is used to supply energy when the LRT is not connected to the supply system. (e.g., battery, electric double-layer capacitor, or flywheel).

In LRT systems for which part of the catenary is eliminated [11-13], the main systems are almost the same as those for other LRT systems; the only difference is the utilization of an energy storage device, which allows the train to operate between charging stations (e.g., in China) or between electrified zones (e.g., in Spain and Japan).

Eliminating the conductor that supplies energy to the train reduces the risk of electric shock, reduces visual pollution, and reduces the required mechanical maintenance since the pantograph or the contact shoes could be eliminated. Magnetic induction can be used for power transfer without galvanic contact between the source and the LRT vehicle. The concept is based on the fact that a variable current flowing in a spiral generates a magnetic flux and a flux passing inside a coil induces current. A magnetic flux does not require a medium to propagate through, allowing the power source and load to be physically and electrically. Various methods based on this concept, called wireless power transfer (WPT), have been developed for supplying power to LRT vehicles.

The operation of WPT for LRT is similar to that of traditional power transfer, where two coils are connected magnetically through a ferromagnetic material. The largest difference is the presence of a large air gap between the primary and secondary sides. To improve power transfer, the input signal is upconverted to dozens of kilohertz using a semiconductor inverter. To minimize inverter complexity, a square wave is normally used. Moreover, compensation circuits are used in the primary and secondary coils to force the system to operate in resonance mode. From the point of view of the source, the circuit behaves as a pure resistive load, which reduces losses and maximizes efficiency.

Since the WPT systems used in transportation are based on power transformers, the coil and core designs are based on traditional mono-phase transformers, which have an E-shaped core with the coil wound around the center leg. The designs differ in terms of the type of transformer shape and the operation. For WPT systems in which energy transfer occurs when the train is running or stopped, the primary coil design tends to have one or two very long turns occupying the whole space of the traction section [14-18] and ferromagnetic materials are positioned along the section to ensure the uniformity of the generated magnetic field. Different designs optimize different parameters, such as weight, power transfer, and loss reduction. These systems, where energy transfer occurs when the train is running or stopped, are often called online WPT.

WPT systems where energy transfer occurs only when the train is stopped are called offline WPT. In these systems, the primary coil and core are called the charging pad, and the secondary coil and core (in the LRT vehicle) are called the receiver. The designs for offline WPT were initially based on power transformers but have since evolved [19]. The core legs have become increasingly small, with planar cores now used in most designs [20]. The charging pad is relatively inexpensive and can be implemented much faster for existing lines compared to catenary systems or online WPT systems. Of note, LRT vehicles based on offline WPT have been used to replace diesel-powered trains in rural areas and to re-introduce passenger service in areas where trains were discontinued to make space for automobiles [1,3].

As mentioned above, the design of an online WPT primary coil allows the generation of a uniform magnetic field. On the other hand, for offline WPT, the positioning of charging pads is a critical issue. Misalignment between the primary and secondary coils greatly affects how the secondary part sees the magnetic field produced by the charging pad, reducing the induced current and thus power transfer. 
When LRT vehicles run on non-segregated tracks, possible misalignment between the primary and secondary coils may occur when the train stops at a station since automatic train operation (ATO) is not used (i.e., the driver must manually stop the train based on experience). Considering trains can have from one to six cars, each $20 \mathrm{~m}$ long, the possibility of misalignment by several centimeters is very high.

Misalignment between coils in WPT can occur in any of the three axes. However, for LRT, misalignment can only occur in the movement direction of the train (along the $\mathrm{x}$ axis) since the receiver is installed in the bogie to ensure a constant air gap (i.e., no changes along the $\mathrm{z}$ axis) and a vehicle that runs on rails has no lateral displacement (i.e., no changes along the y axis). Even with misalignment along only one axis, power transfer is greatly affected [21]. As WPT systems generally use resonance converters, misalignment produces changes in the inductance, and thus the WPT transformer will not operate in resonance mode, with the current and voltage being different from the rated values, increasing losses.

Various methods have been developed to mitigate the effects of misalignment. An actuator that repositions the receiver pad was proposed to compensate for the stopping error of the driver [22]. An autonomous steering system using a sensor coil to maintain the vehicle in the track [23]. A frequency feedback system that changes the input frequency to keep the system operating in resonance mode has been proposed [24]. In both these examples, an additional system is required, increasing complexity. In the case of the actuator, a moving part is added to the system, which negates some of the benefits of WPT, namely reduced maintenance.

The present work proposes a planar coil design for mitigating coil misalignment that maintains WPT system simplicity and adds no moving parts. The proposed design inserts a ferrite material between the turns of the coils. The magnetic material changes the distribution of the magnetic field, making it less sensitive to misalignment.

As the proposed design changes cannot be easily analyzed with a prototype, a three-dimensional (3D) model of the WPT transformer was constructed using finite element method (FEM) software to test various setups of the coils and to investigate the magnetic field. To verify the simulation results, prototype coils were constructed, and the electrical parameters were measured.

To analyze the novel design, the electrical and magnetic theories were used. From the perspective of the electrical circuit, the model presented by Steinmetz [25] was used, due to the simplicity of it. From the point of view of the magnetic analysis, the Maxwell Equations [26] were used, following the interpretation gave by Anele et al. [27], Su et al. [28] and the approach of Luo et al. [29] to use the magnetic vector potential to calculate the mutual inductance.

After the simulation and the construction of the prototype coils was possible to achieve two important results. In the simulation the new design proposed could achieve the best efficiency among the studied coil designs. In the case of the constructed prototypes, when compensation circuit was used the proposed design presented a smaller over value for the input current and output voltage in comparison with the other constructed coils.

The rest of this paper is organized as follows. Section 2 describes the theoretical approach where the electric and magnetic theories used in the work is explained. Section 3 describes the methodology used to create the proposed design in the 3D FEM software and the construction of the prototype. Section 4 presents the description of the simulations performed. Section 5 describes the assembly of the prototype and the performed measurements. Section 6 presents the simulation and measurements results. Section 7 provides the discussion about the results achieved in the work. Lastly, in Section 8 the conclusions of the work are presented along with the related future works.

\section{Theoretical Approach}

This section presents the theoretical background used to develop the proposed design. The effects of misalignment on the WPT transformer are considered in terms of magnetic theory and electric circuit analysis. Maxwell's equations of electromagnetism [26] and magnetic induction based on the 
transformer model proposed by Steinmetz [25] are the starting points for a design of planar coils of a WPT transformer for LRT. The theoretical approach is divided in an electrical analysis and a magnetic analysis.

\subsection{Electrical Analysis}

Several electrical models have been presented for transformers since the first model was proposed by Steinmetz [25]. For transformers with an air gap, such as WPT transformers the selection of model depends on the complexity required to represent the system. The simple model presented by Steinmetz is widely used for WPT transformers. Other models include one that divides the primary and secondary sides based on the value of the coupling coefficient $[30,31]$ and one based on duality between magnetic and electric circuits [21].

In this study, the electrical model was the Steinmetz model due to its simplicity. The analysis of the electric parameters was conducted based on a black box, where the input and output values were measured. For the inductance values, a qualitative analysis of the equations was performed to find optimal values to make the design more robust to misalignment. Figure 1 shows a diagram of the electric circuit model used in this work.

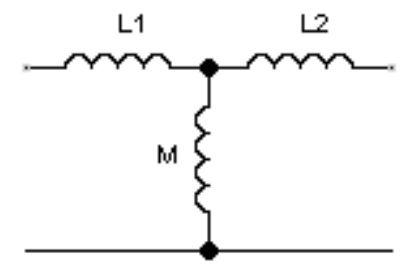

Figure 1. Wireless power transfer (WPT) transformer electric model.

As shown in the figure, the model includes the self- and mutual inductances of the coils.

\subsection{Magnetic Analysis}

The magnetic analysis was conducted using the self- and mutual inductance equations derived from Maxwell's equations. The equations were analyzed using a qualitative approach using both an analytic method and FEM. Self-inductance can be calculated using the mutual inductance equation if the distance between the coils is replaced by the geometric mean distance from a coil to itself [32].

The starting point for calculating mutual inductance is to calculate the inductance between two filaments $[26,32,33]$. The next step is to consider misalignment between the coils. Anele et al. presented solutions for circular coils with lateral and angular misalignment and presented a mutual inductance equation based on elliptical integrals [27]. A similar approach was used by Lee and Lorentz [17], but for the case of coil being a hollow cylinder. Equation (1) presents the mutual inductance of a circular coil in air [27]:

$$
M=\frac{2 \mu_{0}}{\pi} \sqrt{R_{p} R_{s}} \int_{0}^{\pi} \frac{\left[\cos \theta-\frac{d}{R_{s}} \cos \varphi\right] \Psi(k)}{k \sqrt{V^{3}}} d \varphi
$$

where

$$
\begin{gathered}
\alpha=\frac{R_{p}}{R_{s}}, \beta=\frac{c}{R_{p}} \text { and } \xi=\beta-\alpha \cos \varphi \sin \theta \\
k^{2}=\frac{4 \alpha V}{(1+\alpha V)^{2}+\xi^{2}} \\
V=\sqrt{1-\cos ^{2} \varphi \sin ^{2} \theta-2 \frac{d}{R_{s}} \cos \varphi \cos \theta+\frac{d^{2}}{R_{s}^{2}}}
\end{gathered}
$$




$$
\Psi(k)=\left(1-\frac{k^{2}}{2}\right) K(k)-E(k)
$$

with

$$
K(k)=\int_{0}^{\frac{\pi}{2}} \frac{1}{\sqrt{1-k^{2} \sin ^{2} \theta}} d \theta \text { and } E(k)=\int_{0}^{\frac{\pi}{2}} \sqrt{1-k^{2} \sin ^{2} \theta} d \theta
$$

in which $d$ is the lateral misalignment, $\theta$ is the angular misalignment, $R_{p}$ and $R_{S}$ are the distances from the centers of the coils to the reference axis, respectively, and $\varphi$ is the integration angle at any point on the secondary coil. A diagram representing these equations can be found in the study of Anele et al. [27].

In the present study, the coils have magnetic material substrate. On the primary side, a ferrite core is used to increase the magnetic flux and to generate a flux that is reduced non-uniformly as misalignment occurs. On the secondary side, a magnetic film is used as magnet shielding to eliminate induced currents on the LRT car body, which is made from conductors such as stainless steel and aluminum.

Studies on coils with magnetic materials were reviewed. In one study, [33], an inductor was wound around a magnetic bar. In another, a planar inductor with one magnetic substrate was analyzed [34]. In yet another, a planar coil with a magnet substrate was used on the primary and secondary sides [35]. These three studies used the same approach to calculate mutual inductance:

$$
Z=j \omega M+Z_{c}
$$

where $Z$ is the total mutual inductance, $M$ is the mutual inductance calculated for the coil in air using Equation (1), and $Z_{c}$ is the mutual inductance due to the utilization of the magnetic substrate. $Z_{c}$ is a complex number having a real part corresponding to the losses caused by the eddy currents in the magnetic material and an imaginary part that is the increment in the mutual inductance due to the utilization of the magnetic substrate.

The $Z_{\mathcal{c}}$ value for a coaxial filament turn given by Su et al. [28] is as follows:

$$
\begin{gathered}
Z_{c}=\frac{j \omega \mu_{0}}{h_{1} h_{2} \ln \left(R_{p 2} / R_{p 1}\right) \ln \left(R_{s 2} / R_{s 1}\right)} \times \int_{0}^{\infty} S\left(k R_{p 1}, k R_{p 2}\right) Q\left(k h_{1}, k h_{2}\right)[f(\lambda)+g(\lambda)] \\
\times\left(\int_{0}^{\pi} \int_{R_{s 1}}^{R_{s 2}} \frac{R_{s}-d \cos \varphi}{r} J_{1}(k r) d R_{s} d \varphi\right) d k
\end{gathered}
$$

where

$$
\begin{gathered}
Q(k x, k y)\left\{\begin{array}{c}
=\frac{2}{k}\left[\cos h k \frac{x+y}{2}-\cos h k \frac{x-y}{2}\right], z>\frac{h_{1}+h_{2}}{2} \\
=\frac{2}{k}\left(h+\frac{e^{-k h}-1}{k}\right), z=0, x=y=h
\end{array}\right. \\
S(k x, k y)=\frac{J_{0}(k x)-J_{0}(k y)}{k} \\
f(\lambda)=\frac{\lambda\left(t_{1}, t_{2}\right) e^{-k\left(d_{2}+d_{1}\right)}+\lambda\left(t_{3}, t_{4}\right) e^{-k\left(d_{2}^{\prime}+d_{1}^{\prime}\right)}}{1-\lambda\left(t_{1}, t_{2}\right) \lambda\left(t_{3}, t_{4}\right) e^{-2 k s}} \\
g(\lambda)=\frac{2 \lambda\left(t_{1}, t_{2}\right) \lambda\left(t_{3}, t_{4}\right) e^{-2 k s} \cos h\left[\lambda\left(d_{2}-d_{1}\right)\right]}{1-\lambda\left(t_{1}, t_{2}\right) \lambda\left(t_{3}, t_{4}\right) e^{-2 k s}}
\end{gathered}
$$

with

$$
\begin{aligned}
& \lambda\left(t_{1}, t_{2}\right)=\frac{\varphi_{1}(k)+\left(\theta\left(t_{2}\right)-m / \theta\left(t_{2}\right)+m\right) e^{-2 \eta_{1} t_{1}}}{1+\varphi_{1}(k)\left(\theta\left(t_{2}\right)-m / \theta\left(t_{2}\right)+m\right) e^{-2 \eta_{1} t_{1}}} \\
& \lambda\left(t_{3}, t_{4}\right)=\frac{\varphi_{1}(k)+\left(\theta\left(t_{4}\right)-m / \theta\left(t_{4}\right)+m\right) e^{-2 \eta_{1} t_{3}}}{1+\varphi_{1}(k)\left(\theta\left(t_{4}\right)-m / \theta\left(t_{4}\right)+m\right) e^{-2 \eta_{1} t_{3}}}
\end{aligned}
$$


and

$$
m=\frac{\mu_{r 1} \eta_{2}}{\mu_{r 2} \eta_{1}}, \theta\left(t_{i}\right)=\frac{1-\varphi_{2}(k) e^{-2 \eta_{2} t_{i}}}{1+\varphi_{2}(k) e^{-2 \eta_{2} t_{i}},}, \begin{aligned}
& \eta_{1}=\sqrt{k^{2}+j \omega \mu_{r 1} \mu_{0} \sigma_{1}} \\
& \eta_{2}=\sqrt{k^{2}+j \omega \mu_{r 2} \mu_{0} \sigma_{2}}
\end{aligned}, \begin{aligned}
& \varphi_{1}(k)=\frac{\mu_{r 1}-\left(\eta_{1} / k\right)}{\mu_{r 1}+\left(\eta_{1} / k\right)} \\
& \varphi_{2}(k)=\frac{\mu_{r 2}-\left(\eta_{2} / k\right)}{\mu_{r 2}+\left(\eta_{2} / k\right)}
\end{aligned}
$$

in which $J_{1}$ is the Bessel function of the first kind.

Previous studies $[28,33,34]$ presented analytical solutions for the inductance calculations for their respective specific configurations, and proposed an integral calculation that is faster and easier compared to FEM, not the scope of this work.

Equations (1) and (15) were used to calculate one turn. For multiturn filament coils, the superposition principle was used [29,36]:

$$
M_{\text {total }}=\sum_{i=1}^{n_{e}} \sum_{j=1}^{n_{r}} M_{i j}
$$

Using Equations (1)-(16), it is possible to qualitatively analyze how misalignment affects the values of mutual inductance and self-inductance. For a qualitative point of view, the output values of the electrical parameters are proportional to the mutual inductance, and thus it is possible to analyze how the system will behave. This analysis can be done for a spirally wound coil. Moreover, the novelty proposed in the current work cannot be analyzed using the presented equations.

The utilization of a magnetic material layer between coil turns makes previous theoretical approaches unsuitable. Luo et al. [29] calculated mutual inductance by solving Poisson's equation when the vector potential is satisfied:

$$
\nabla^{2} \vec{A}=-\mu J
$$

In the study of Luo et al., the current density was excited by a sinusoidal current and the partial derivative equations were constructed for each region selected by the authors. The equations were then solved using the Fourier-Bessel integral transformation and equations similar to those presented above were obtained, the solution was presented for each of the defined regions and the mutual inductance was calculated in the region of the secondary coil where the current in the primary coil had an effect. In the present study, the relationship of the magnetic vector potential and the mutual inductance is used.

To qualitatively analyze the effect of introducing a magnetic material between the turns of the coil, a study of the magnetic vector potential was conducted to determine how its value varies for different designs of a 3D FEM model. The magnetic vector potential was calculated for various misalignment values. As mentioned above, the output values are proportional to the mutual inductance of the coils. These values were thus analyzed to fully understand the effect of the magnetic material layer between the coil turns when misalignment occurs.

\section{Methodology}

Improvements to the design of a planar WPT transformer that could reduce the effects of misalignment in the output electric parameters are proposed in this topic, the methodology used during the research will be presented and explained.

\subsection{Modeling}

The starting point for this research was the simplest approach for a WPT transformer for an offline WPT system for LRT, namely a round planar coil with a magnetic material used to increase the magnetic flux. As shown in [37], it is possible to use a magnetic material only on the primary side and still generate enough flux to induce the required amount of power on the secondary side. In [37], the possible eddy currents induced in the train carbody were not taken into consideration. As shown 
in Tan et al. [38] and in Wen and Huang [39], the presence of a metallic plate to the WPT transformer affects the inductance values and the generated eddy currents could generate important losses.

To prevent these effects, an amorphous magnetic material was used in this work. To maintain the weight reduction obtained with the elimination of the magnetic material on the secondary side and consider the eddy currents induced in the carbody, an amorphous magnetic film [40] was proposed as a shielding material and used in a 3D model and prototype.

In the present study, the WPT transformer was constructed as a round coil with ferrite as a substrate on the primary side, the secondary side was formed by a coil, an amorphous magnetic material was used for shielding, and an aluminum plate was used to represent an LRT carbody. A previous study [41] showed that the turn ratio of a loosely coupled transformer is the ratio of the self-inductances of the coils. The value of the mutual inductance in the theoretical approach depends on the turn ratio. To keep the analysis simple, the coils were constructed with the same turn number, so the self-inductances tended to be similar (i.e., the turn ratio was as close as possible to one).

To analyze the vector potential in the theoretical approach, a 3D model of the WPT transformer was constructed in FEM software. Since the goal was to construct an improved design that maintains the desirable characteristics and has similar construction costs and assembly complexity, a round planar coil was used in all models.

The 3D models were created in JMAG software (JSOL Corporation, Tokyo, Japan) [42]. Since the models were symmetrical, half models were used to speed up calculation. In JMAG, for each of the parts described above, a structure was created. Figure 2 shows an example 3D model.

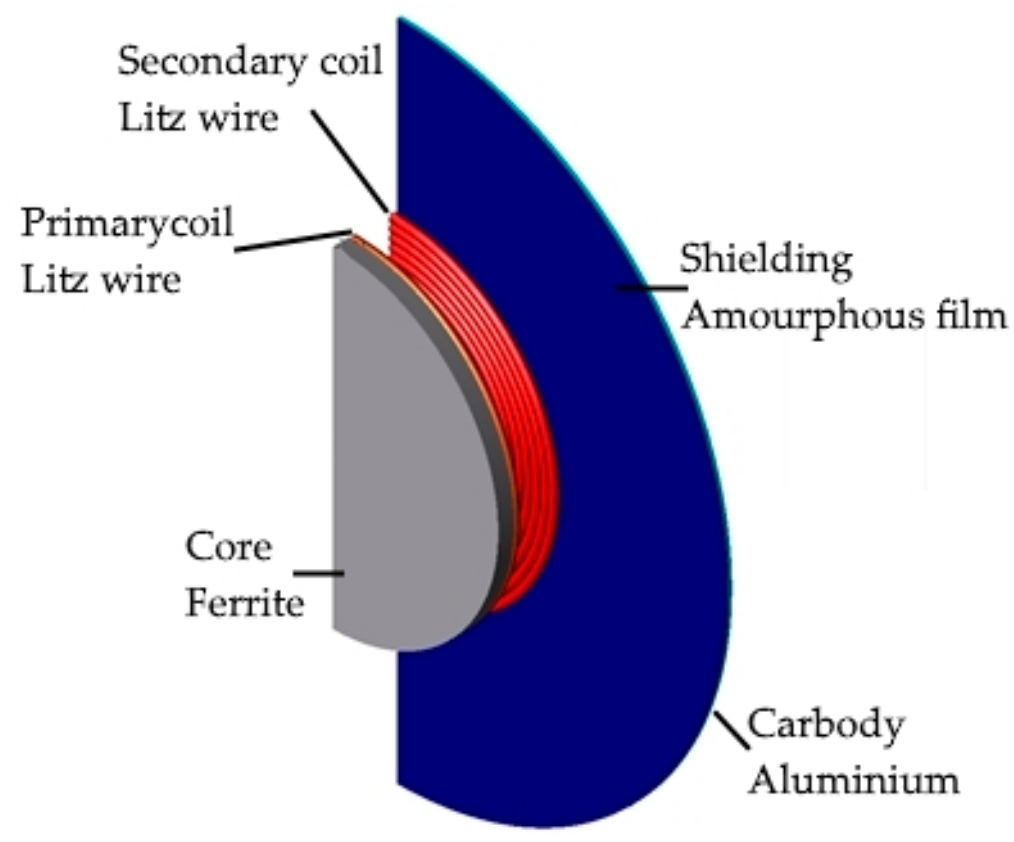

Figure 2. Half model of WPT transformer.

The coils in all models were constructed as cylinders that follow a spiral arc for each turn, as shown in Figure 2. The decision of constructing one cylinder for each turn was important since the proposed designs presented magnetic material layer between the coil turns. For the primary core, the shape was circular and considered as unique block. The amorphous magnetic film shield and the carbody were modeled to have the same size but different thicknesses.

Positioning was the next step. For construction simplicity, the structures were stacked respecting the distances used in the prototype. The air gap between the primary and secondary coils was fixed in this study since in real WPT systems, the secondary coil is installed in the bogie of the LRT vehicle, ensuring that there will be no changes in the air gap at different charging stations. 
Misalignment in WPT systems for LRT only occurs in the train movement direction. To emulate this, the secondary side (coil, shield, and carbody) was moved along the y axis from the position where the coils were totally aligned until the position where the center of the secondary was at the top of the edge of the primary side, as shown in Figure 3.

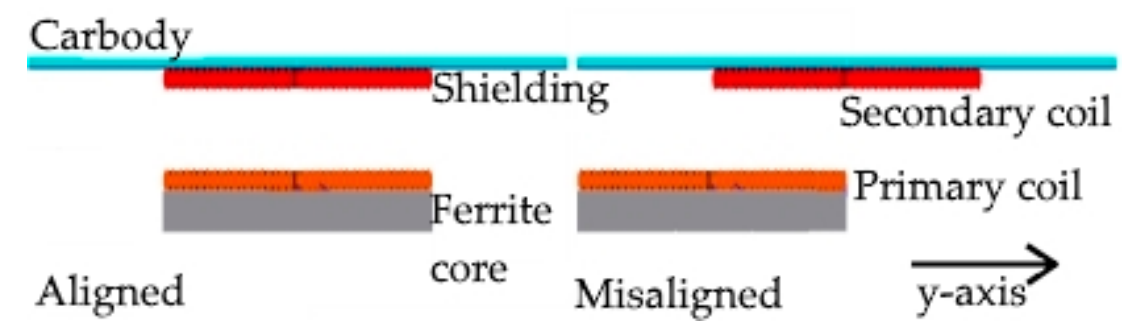

Figure 3. Diagram showing coil misalignment.

The size of the model was based on the constraints of the prototype for the wire diameter, ferrite block size, and shielding film thickness. The WPT transformer had a size constraint as well; there was a maximum value of the coil diameter.

Taking these constraints into consideration, the first model, referred to as tide hereafter, was constructed as shown in Figures 2 and 3. In the tide model, the spirally wound coil is tide wounded on the top of a solid ferrite base. The component sizes are given in detail later. To study the effect of the magnetic material between the coils on misalignment sensitivity, an open-wound spiral was constructed. The separation between turns was equal to the size of the magnetic material blocks available in the laboratory. The model is referred to as spiral hereafter. The next model is the spiral model with a magnetic material layer between the turns, referred to as intercore spiral.

The tide, spiral, and intercore spiral models were analyzed to determine the effect of the magnetic material on the electrical parameters. Based on the results, a novel design was defined, where the magnetic material layer between the turns is used in the area with a higher concentration of magnetic flux, the center of the coil, and the tide winding on the outer area of the coil. This model is referred to as hybrid intercore. Figure 4 shows the four models.
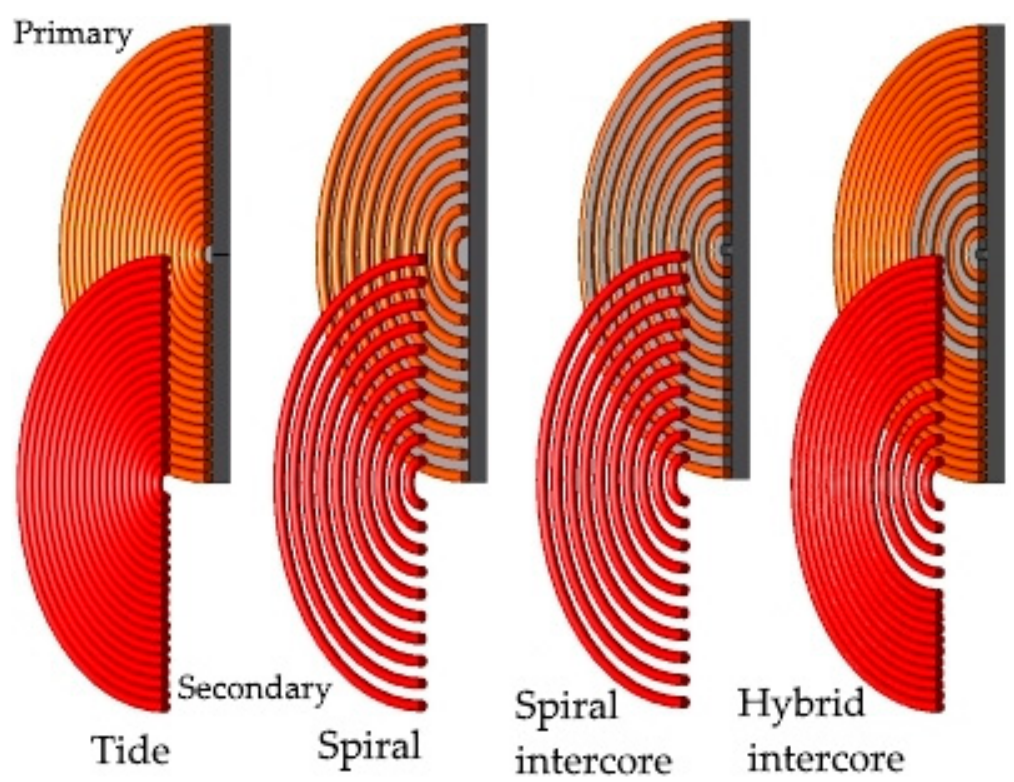

Figure 4. Diagram of four model types.

The secondary coils were constructed with the same designs, as also shown in Figure 4 . 


\subsection{Prototype Construction}

To ensure that an arbitrary misalignment could be produced in the $\mathrm{x}, \mathrm{y}$, and $\mathrm{z}$ axes, a special support was designed. The primary side was installed in a polycarbonate base that could move in the $x$ axis direction. The secondary side was installed in a polycarbonate base attached to a moving cart that allowed the system to move in the $\mathrm{y}$ and $\mathrm{z}$ axis directions. Figure 5 shows the $\mathrm{x}-\mathrm{y}-\mathrm{z}$ movement base.

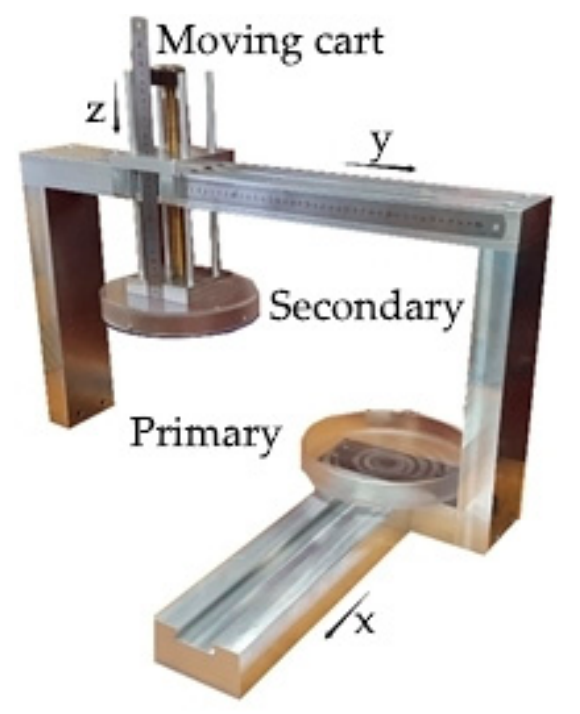

Figure 5. Movement base.

The coils were constructed using litz wire to reduce the proximity effect and eddy currents between the turns. The detailed characteristics of litz wire can be found elsewhere [37]. The coil shape was preliminarily designed using computer-aided design (CAD) software to ensure that the total size and turn positions met the support base constraints. Printouts of the design were attached to plastic films with double-sided tape to maintain the desired litz wire winding design. In industrial applications, an adhesive coating is used to maintain the shape of the coil. Figure 6 shows an example of the constructed coil.

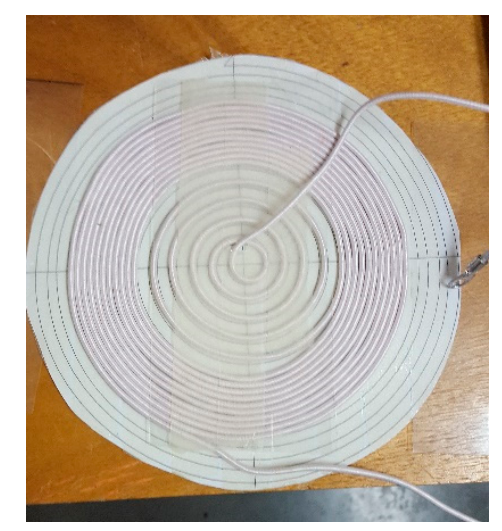

Figure 6. Hybrid intercore coil.

For core construction, since the ferrite blocks were rectangular parallelepipedal in shape, the shape of the final core was an adaptation of the core constructed in FEM software. To attach the ferrite blocks, adhesive tape was used to maintain the blocks in position when misalignment was created by moving the cart. 
For shielding, films were joined and installed in a wood frame. The full shield was enclosed in the moving base. A space was created to allow movement of the cart during measurements. Figure 7 shows the shielding film installed in the moving base.

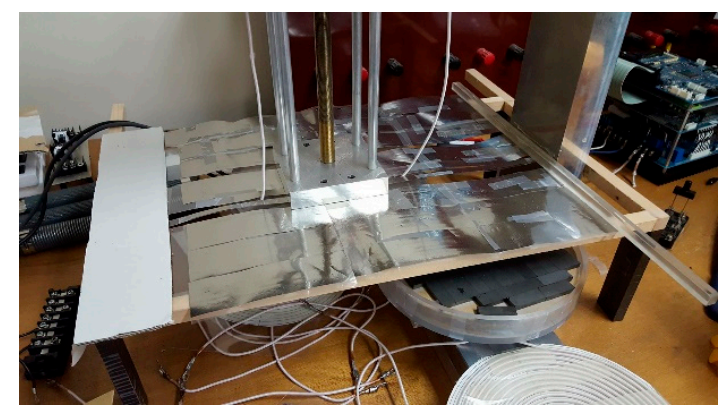

Figure 7. Shielding film.

\section{Simulation}

This section presents the simulations of designs shown in Figure 4. The values used for the wire diameter, ferrite block size, and shielding thickness are based on the available material in the laboratory. To study the effect of the ferrite material layer between the coil turns, the coils were made to be the same size. The effect on the magnetic flux and the vector potential could thus be better understood.

The WPT transformer shown in Figure 2 had a circular shape. The coil designs used in the simulation followed those in Figure 4. The coil material was defined as copper. The magnetic material used for the primary side was ferrite. For the secondary side, no magnetic material was used. For the shielding and the car body, a circular shape was used. The shielding material was modeled using the values from the material datasheet [40]. For the car body, aluminum was used.

Table 1 presents the values used in all designs, and Table 2 shows the model-specific values.

Table 1. Common values used in models.

\begin{tabular}{ccccccccc}
\hline $\begin{array}{c}\text { Air } \\
\text { Gap }\end{array}$ & $\begin{array}{c}\text { Coil } \\
\text { Diameter }\end{array}$ & $\begin{array}{c}\text { Wire } \\
\text { Diameter }\end{array}$ & $\begin{array}{c}\text { Ferrite } \\
\text { Diameter }\end{array}$ & $\begin{array}{c}\text { Ferrite } \\
\text { Width }\end{array}$ & $\begin{array}{c}\text { Shielding } \\
\text { Diameter }\end{array}$ & $\begin{array}{c}\text { Shielding } \\
\text { Width }\end{array}$ & $\begin{array}{c}\text { Carbody } \\
\text { Diameter }\end{array}$ & $\begin{array}{c}\text { Carbody } \\
\text { Width }\end{array}$ \\
\hline $10 \mathrm{~mm}$ & $82 \mathrm{~mm}$ & $2 \mathrm{~mm}$ & $82 \mathrm{~mm}$ & $4 \mathrm{~mm}$ & $164 \mathrm{~mm}$ & $0.1 \mathrm{~mm}$ & $164 \mathrm{~mm}$ & $1 \mathrm{~mm}$ \\
\hline
\end{tabular}

Table 2. Model-specific values.

\begin{tabular}{cccc}
\hline Coil Design & Turns & Intercore Ferrite Width & Intercore Ferrite Layers \\
\hline Tide & 19 & - & - \\
Spiral & 10 & - & - \\
Intercore & 10 & $2 \mathrm{~mm}$ & 10 \\
Hybrid & 15 & $2 \mathrm{~mm}$ & 5 \\
\hline
\end{tabular}

The models were constructed using the designer tool of JMAG software. For each part of the WPT transformer, a structure was assembled, and the material was selected. The mesh for the calculation was created using the generator provided in the software with a fixed element size to ensure a minimum quality of the generated mesh. The air region used in the calculation was 1.1 times the length of the constructed model and five times the height.

The next step was the creation of the misalignment. To create misalignment, the secondary side was moved with respect to the primary side. To decrease the calculation time and memory usage, the displacement was done in the designer tool and not in the simulation tool (as misalignment increases, the size of the mesh would have to be increased since the area occupied by the parts would increase). 
Since the software did not have to recalculate the mesh for each movement of the secondary side, calculation was sped up since the model creation step already set the boundaries for mesh creation.

Since the sizes of the studied models were the same, the misalignments used in the simulations were the same. In previous work [21], 5 values of misalignment were used in the study and total misalignment was considered to occur when the secondary side was totally outside the primary side. It was observed that with misalignment, as the secondary side is moved away from the center of the primary side, the power that can be transmitted becomes smaller than that obtained when the sides are aligned until the misalignment reaches half the size width of the primary side, at which point no power is transmitted. Total misalignment is here defined as the secondary side being misaligned by half width of the primary side.

To better illustrate the results, 9 values of misalignment, in increments of $1 / 8$ the diameter of the coil, were used. Sufficiently good results were obtained with a reasonable calculation time (average of 1 to 2 hours per simulation).

The simulations were performed using magnetic field analysis tool with frequency response analysis in JMAG. An electric circuit was created for calculation. In the circuit, each turn of the coil was represented by a FEM conductor entity. The input signal was a sine wave with an amplitude of $1 \mathrm{~V}$, and the load was defined as a $5 \Omega$ resistor. The switching frequency was set to $20 \mathrm{kHz}$ to match the prototype inverter switching frequency. The A-phi algorithm was used for calculation. The circuit is presented in Figure 8.

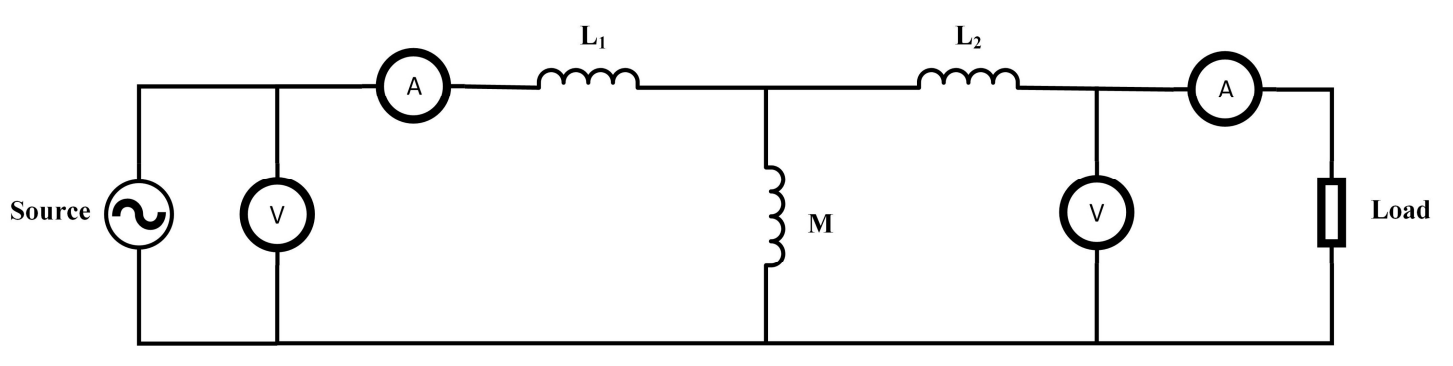

Figure 8. Electric circuit, pure resistive load, used in simulations.

For the frequency analysis in JMAG, the results can be given as a table or visualized (e.g., contour plots, vector plots, or flux lines). For the present work, results were obtained for various misalignment values and graphs were created. A contour plot and a vector plot showing the magnetic field and the magnetic vector potential are also presented herein. The results were obtained for a phase angle of $45^{\circ}$ to avoid singularities. The images for each one of the simulated misalignment are going to be combine in one figure and presented further.

\section{Measurements}

Measurements were performed on the constructed prototype to verify the simulation results and investigate how the utilization of a magnetic material installed between the turns of the coil affects the electric parameters in practice. The WPT transformer prototypes were constructed using the coil and core designs presented in Figure 4. The simulations showed that the intercore spiral is not significantly different from the spiral; this can be attributed to the uniform distribution of the magnetic material in the coil.

The coils, constructed using the method described in the Methodology section, were positioned in the polycarbonate bases as shown in Figure 5. The secondary coil was connected to a precision high-power resistor with a resistance of $5 \Omega$, and the primary side was connected to a connector that was directly attached to the power supply or to a compensation capacitor. As shown in Figure 9, the resistor was attached to the top of the cart to ensure that the positions of the wires of the secondary coil would not change with displacement. The measurement points for the experiments were the output of 
the power supply and the resistor. The current and voltage were measured. The circuit diagram is shown in Figure 8.

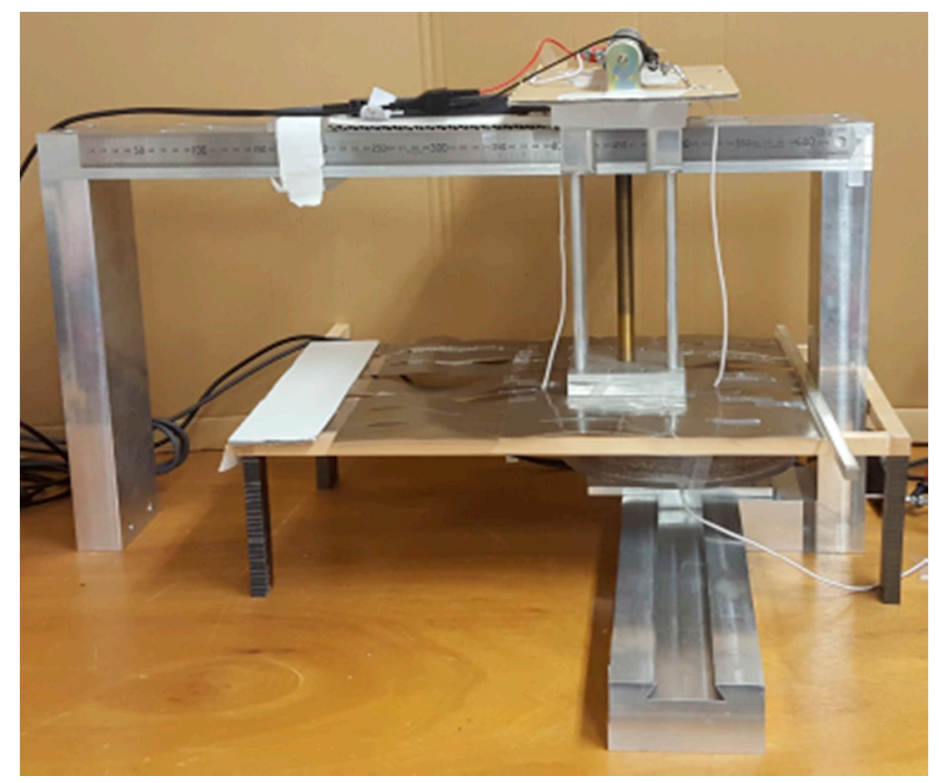

Figure 9. Prototype assembly.

In this work, a Hioki 8855 Memory HiCorder was used to measure and store the input and output electrical parameters (current, voltage, and power). The root-mean-square (rms) values were obtained using a normal voltage probe and the current was measured using a current probe (Hioki 3273-50 Clamp Probe). The power was calculated in the Memory HiCorder. The apparent power was calculated as the product of the rms values of the current and voltage; the active power was calculated as the average of the product of the rms values of the current and the voltage.

The magnetic frequency analysis in JMAG uses a sine wave as the input signal for the calculations. A sine wave with a frequency of $20 \mathrm{kHz}$ and an amplitude of $1 \mathrm{~A}$ was used as the input signal for the measurements. To create the sine wave, a wave generator (NF Wavefactory WF $194612 \mathrm{CH}$ attached to a power amplifier (NF HAS 4052) was used.

In practical WPT systems, the utilization of sine waves is very rare. Most systems use square waves for simplicity to compensate for the inductive characteristics of the system and reduce the required number capacitors. The utilization of capacitors for compensation causes integration of the input signal, meaning that if the utilized waves are different from sine waves, distortions will occur if the compensation is not perfect. To study the response of the proposed design to square waves and compensation, a setup with an inverter unit (Myway Plus Corporation MWINV-5R022). The circuit is presented in Figure 10.

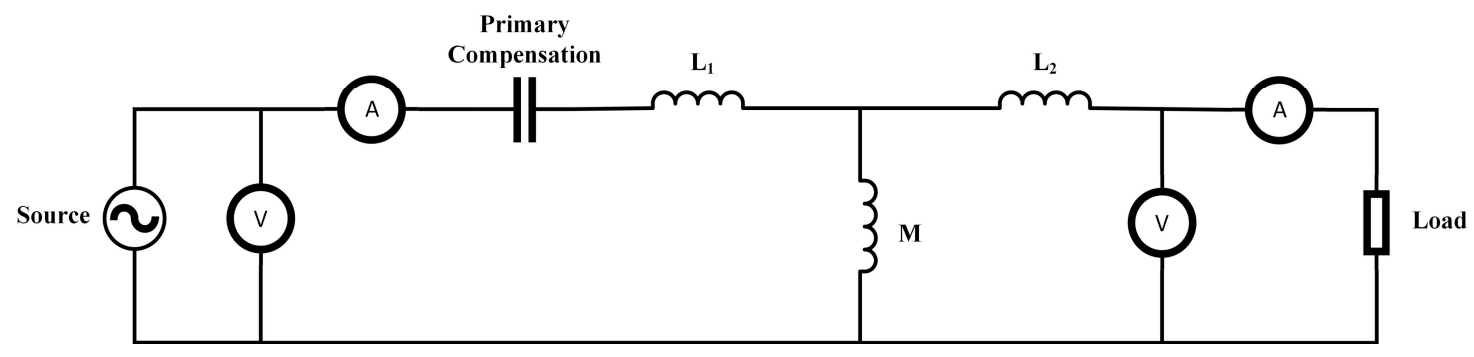

Figure 10. Electric circuit: primary compensation with resistive load. 
The values of the current, voltage, and power were measured starting from the aligned position until total misalignment in intervals of $5 \mathrm{~mm}$. Since the sizes of the constructed coils were different from those used in the simulations, the results were parameterized to allow comparison. The values of misalignment were defined in terms of the width of each of the coils. The electrical parameters at alignment were considered the reference values and defined as 1 per unit value (pu); the values at misalignment were converted to pu values based on the aligned values.

\section{Results}

This section presents the simulation and measurements results, which are given separately for clarity and easier understanding.

Firstly, the results from the simulations are presented in terms of electric parameters and visual representations of the magnetic field. Then, the results from the measurements of the constructed prototype are given.

To compare all results, misalignments were parameterized and are presented as percentages. Herein, $0 \%$ represents alignment, as shown on the left side of Figure 3, and $100 \%$ represents total misalignment, as shown on the right side of Figure 3.

For the magnetic field representations, the color gradient has the same range for all models and misalignments.

\subsection{Simulation Results}

The simulation results were gathered in two sets, the first set of results were the electric parameters, which were gathered in an electronic table, the second set in a group of figures.

\subsubsection{Graphs}

The simulation results are presented as electrical parameters, given in a table, and as figures. From the values given in the table, the current, voltage, active power, and efficiency are plotted in Figures 11-14, respectively. The input voltage was used as the reference parameter for the simulation.

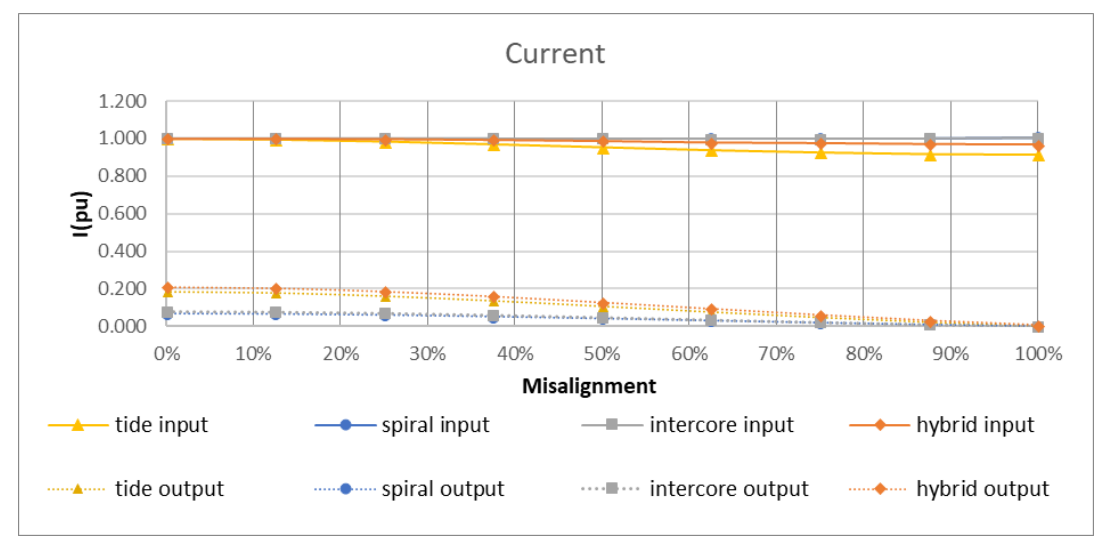

Figure 11. Simulation current. 


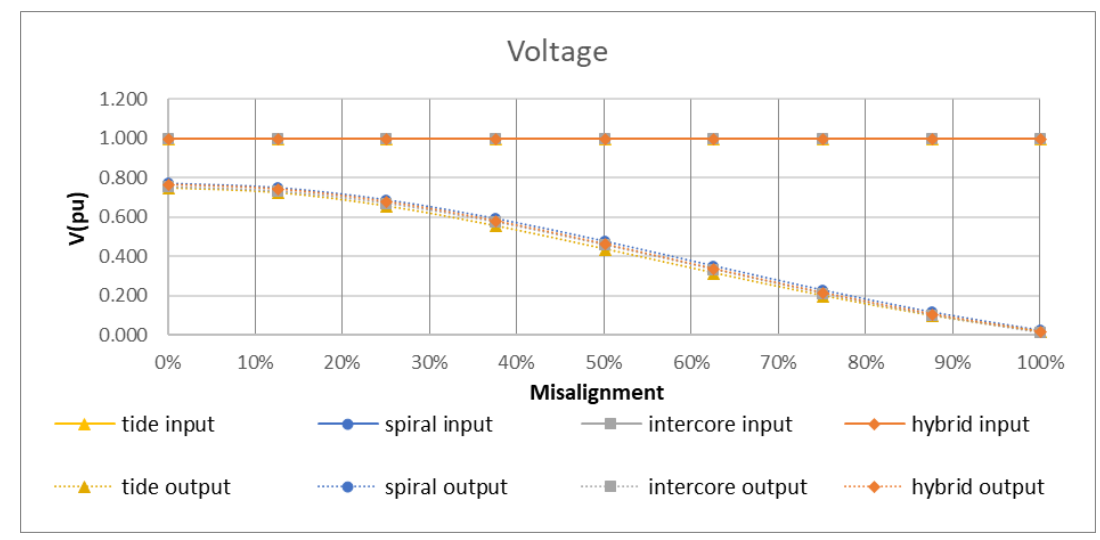

Figure 12. Simulation voltage.

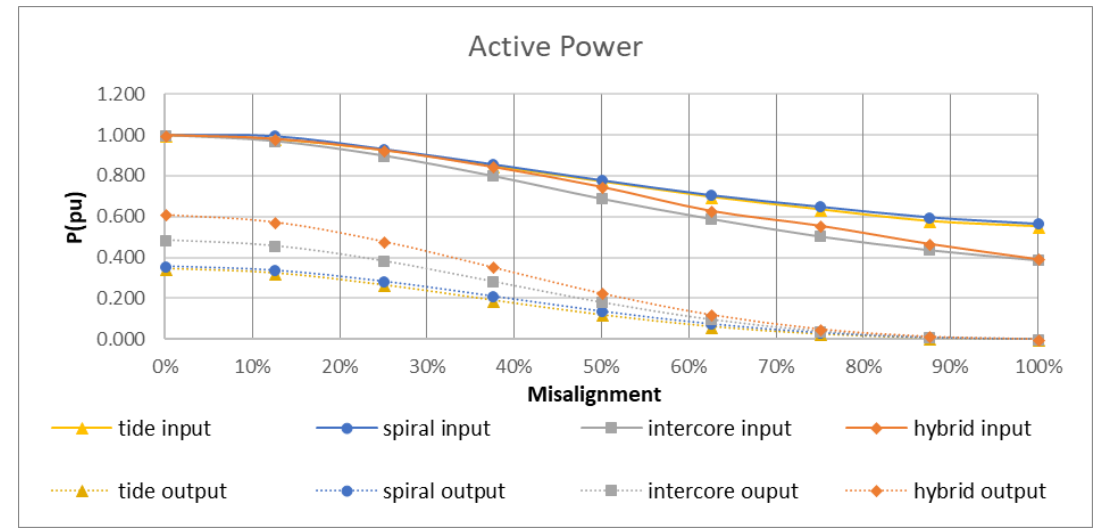

Figure 13. Simulation active power.

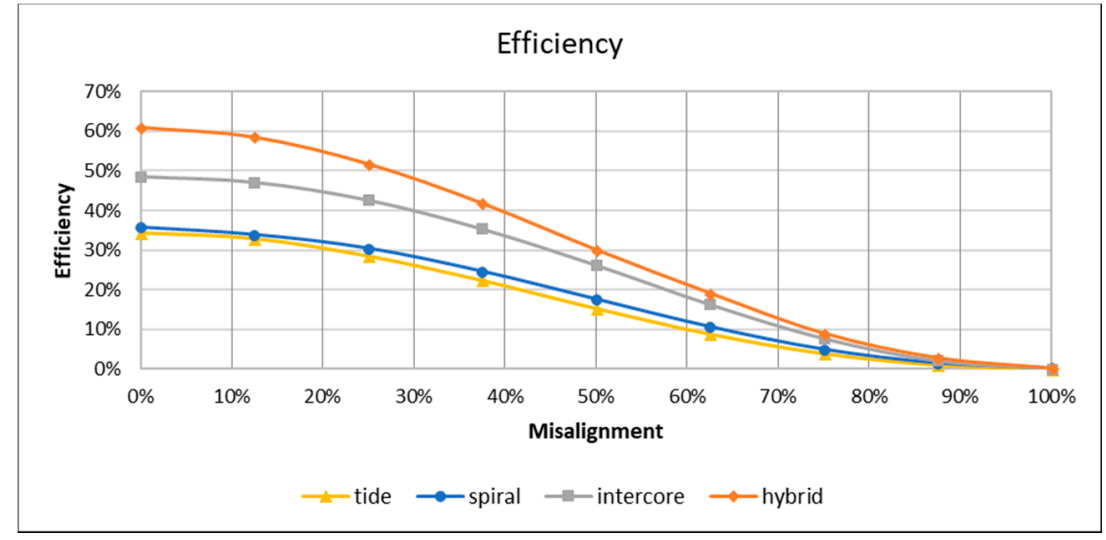

Figure 14. Simulation efficiency.

\subsubsection{Visual Representation}

The contour plot in Figure 15 shows the magnetic field strength. 


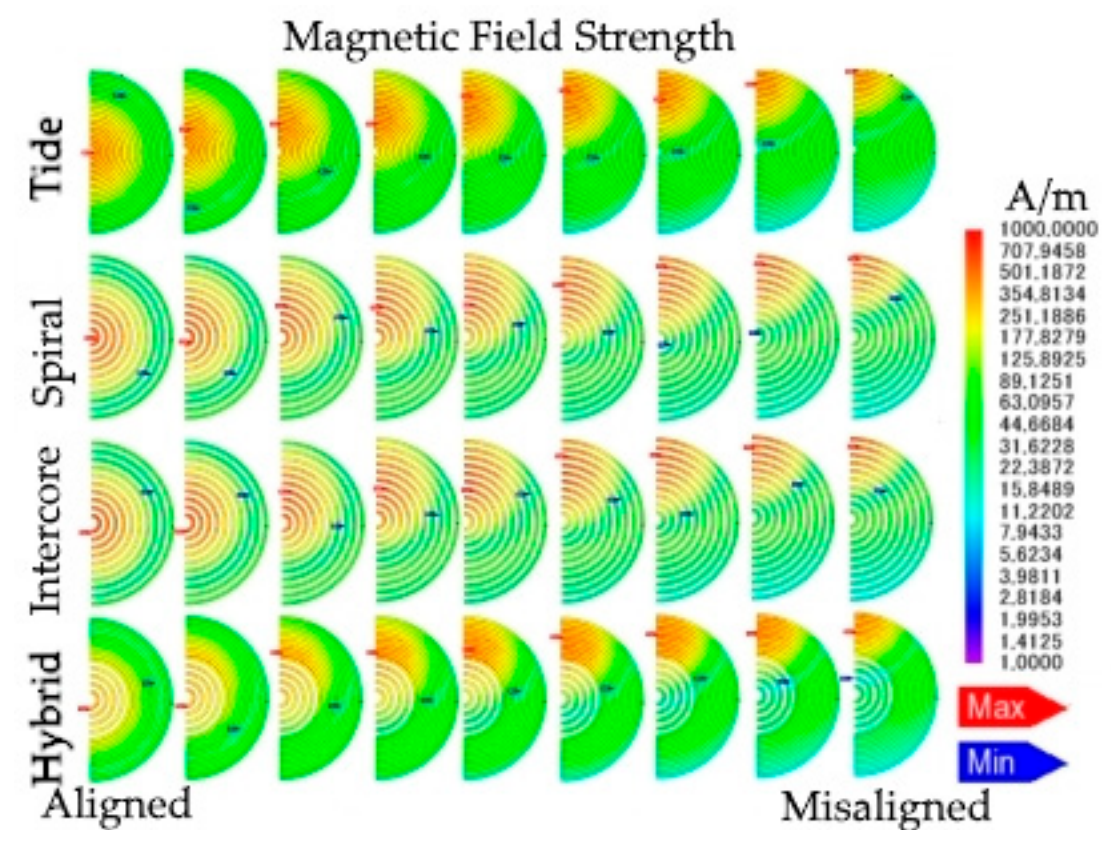

Figure 15. Magnetic field strength.

A vector plot of the magnetic vector potential is presented in Figure 16. Magnified views are shown in Figure 17.

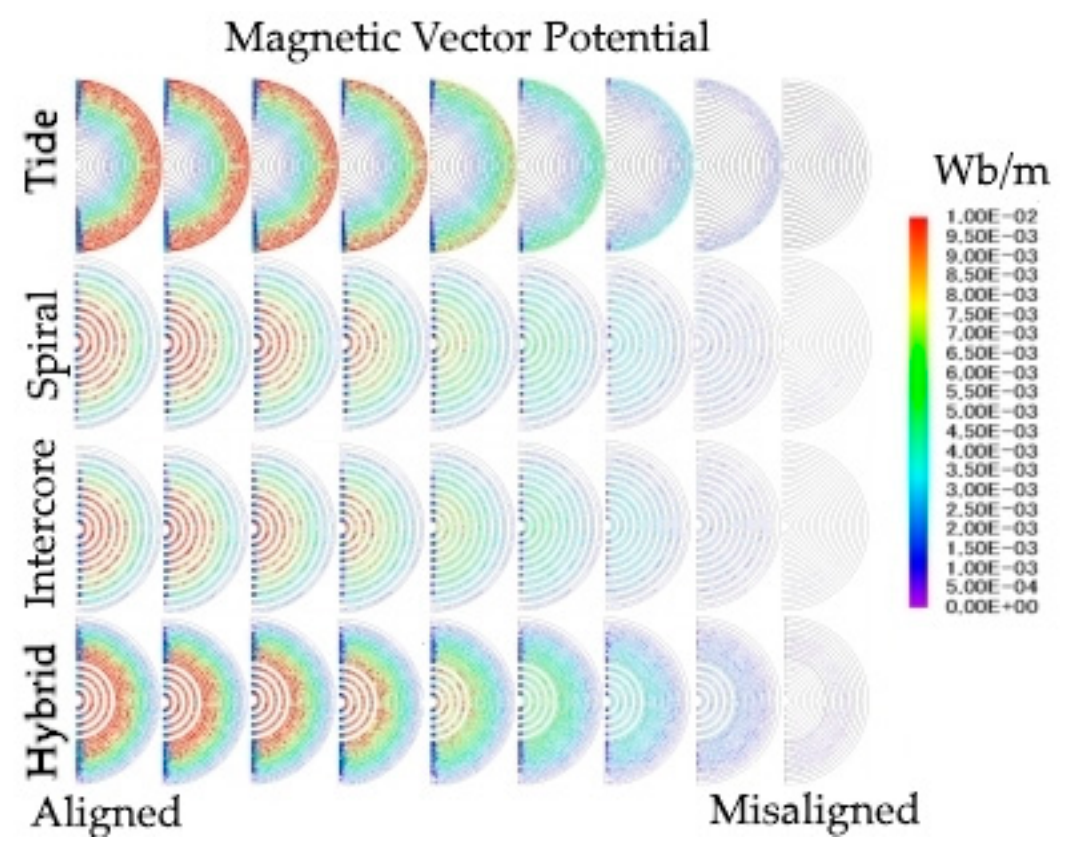

Figure 16. Magnetic vector potential. 


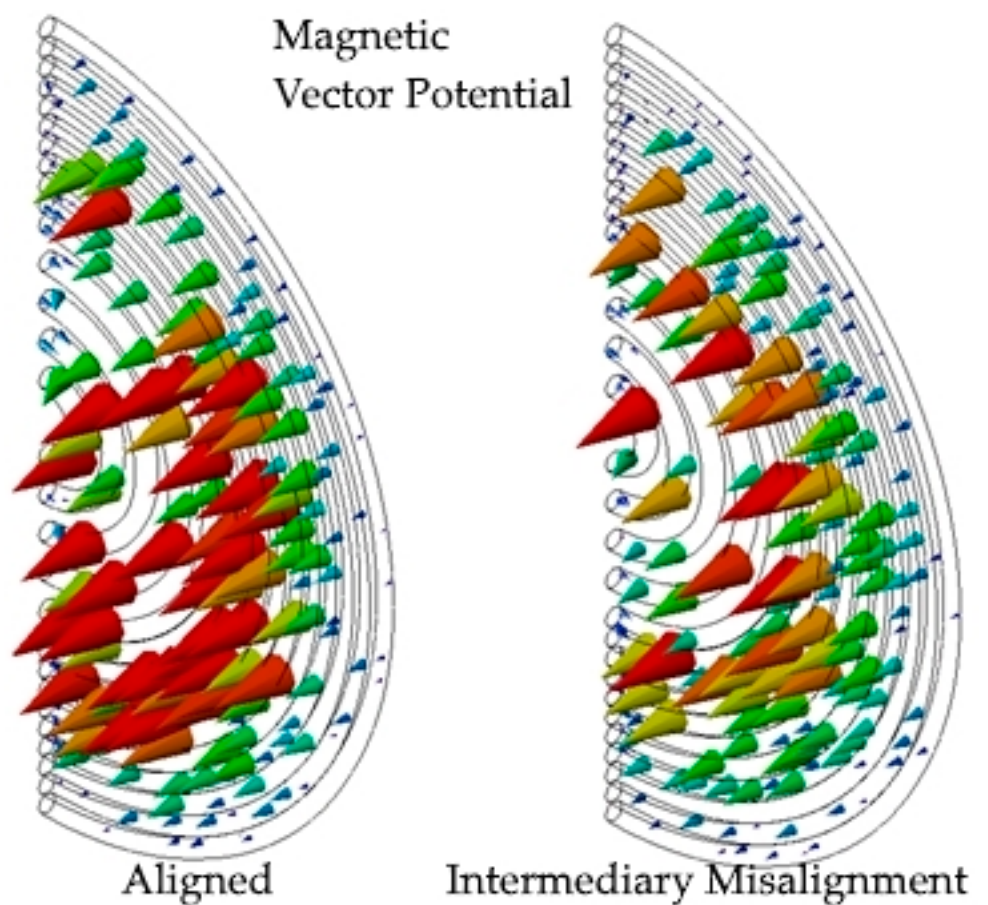

Figure 17. Magnified views of magnetic vector potential of hybrid intercore coil.

\subsection{Measurements Results}

The results of measurements were grouped based on the type of circuit configuration, namely pure resistive load (see Figure 8) and resistive load with primary compensation (see Figure 10). For the pure resistive load, the results are presented for both sine and square waves, and for the compensation setup, the results are presented for only square waves.

\subsubsection{Pure Resistive Load}

To show that changes in the input signal did not affect the results, measurements were obtained for the different coils for both sine and square waves. Figures 18-23 present the input and output current, output voltage, input and output active power, and efficiency for the pure resistive load configuration, respectively.

The input voltage was used as a reference and thus for all misalignments, its value is $1 \mathrm{pu}$.

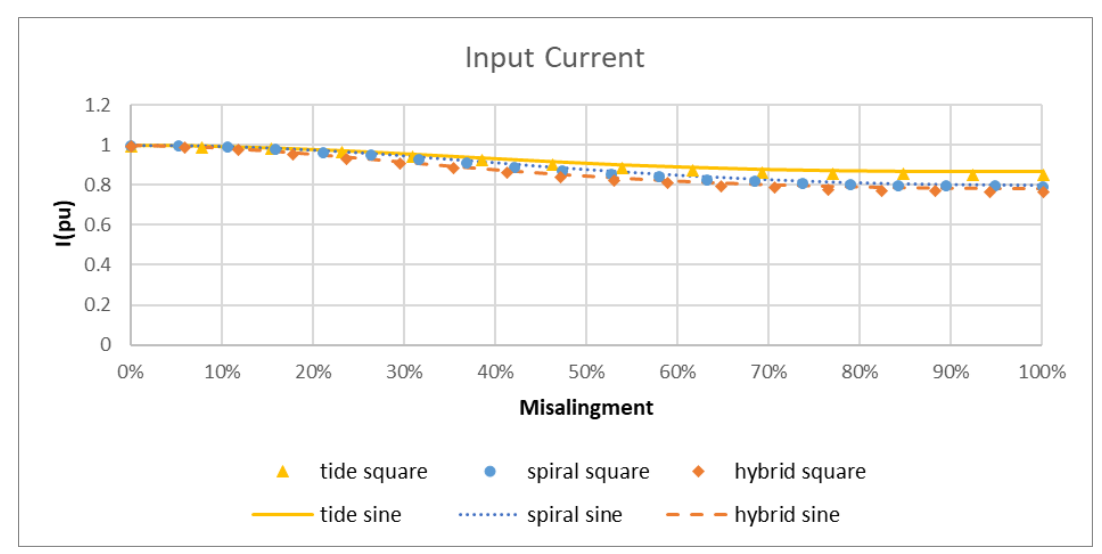

Figure 18. Measured input current for pure resistive load. 


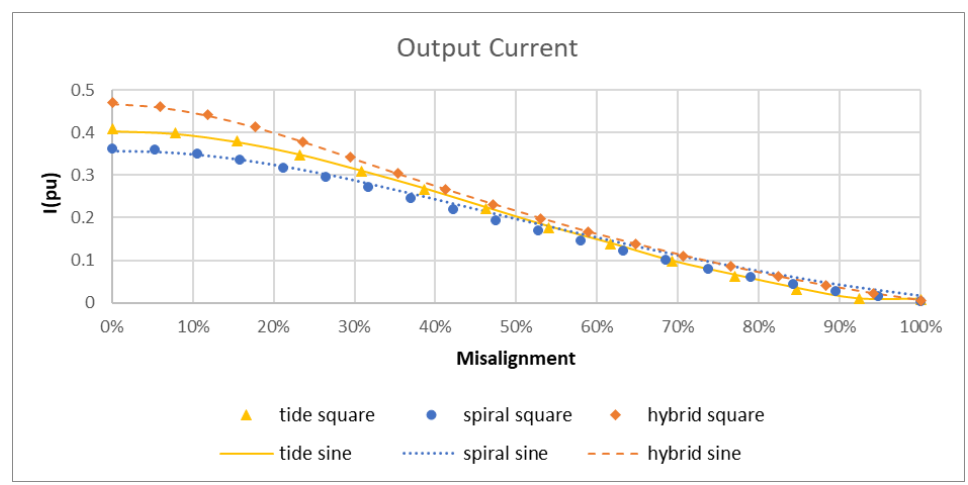

Figure 19. Measured output current for pure resistive load.

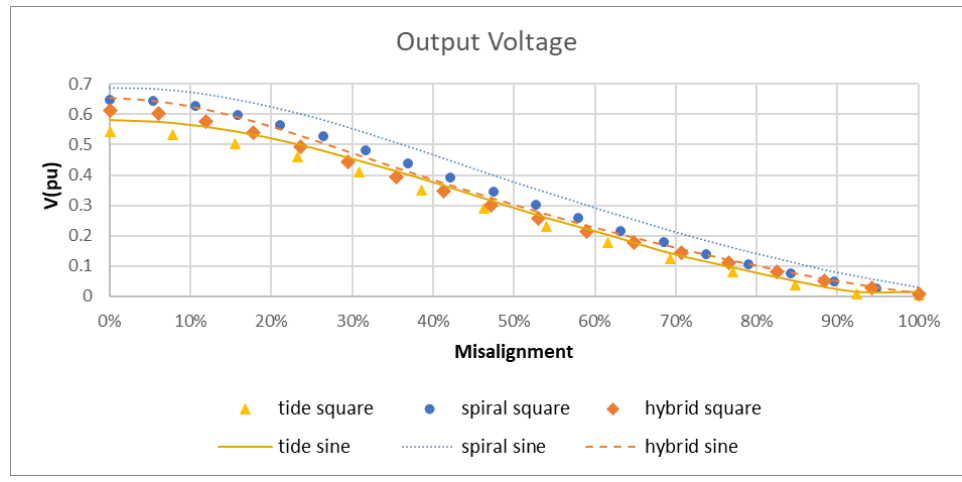

Figure 20. Measured output voltage for pure resistive load.

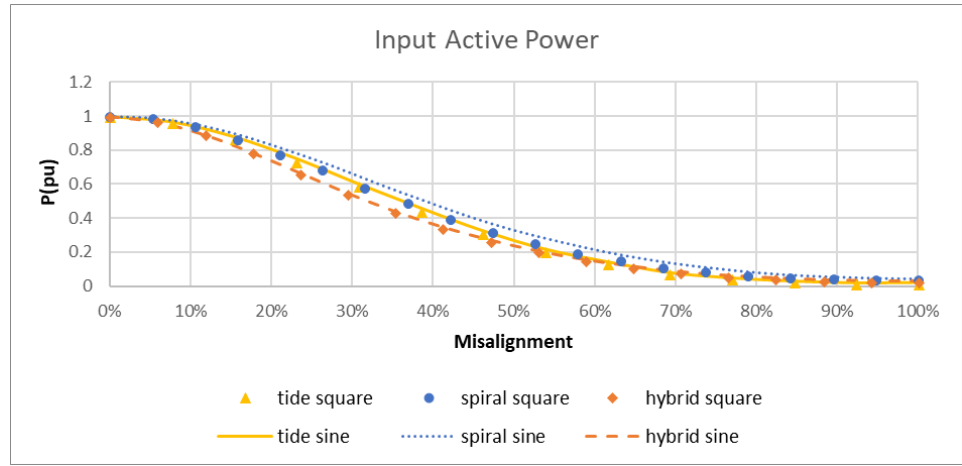

Figure 21. Measured input active power for pure resistive load.

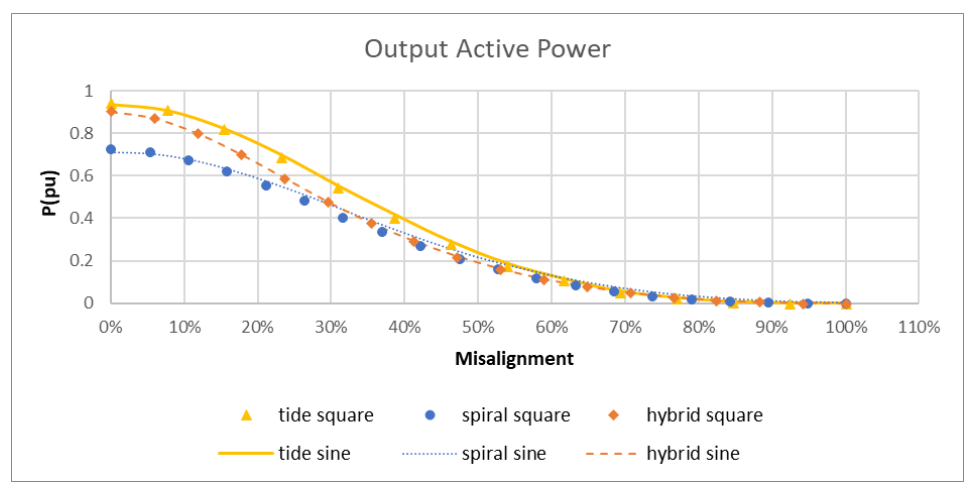

Figure 22. Measured output active power for pure resistive load. 


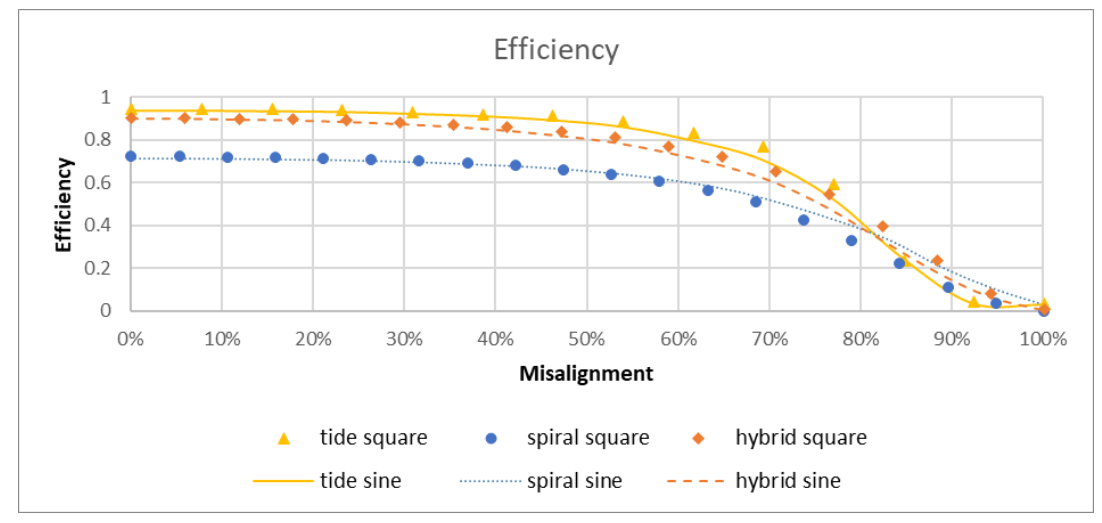

Figure 23. Measured efficiency for pure resistive load.

\subsubsection{Primary Compensation with Resistive Load}

The results for the circuit with primary compensation with a resistive load are presented in Figures 24-27, which show the current, voltage, active power, and efficiency, respectively.

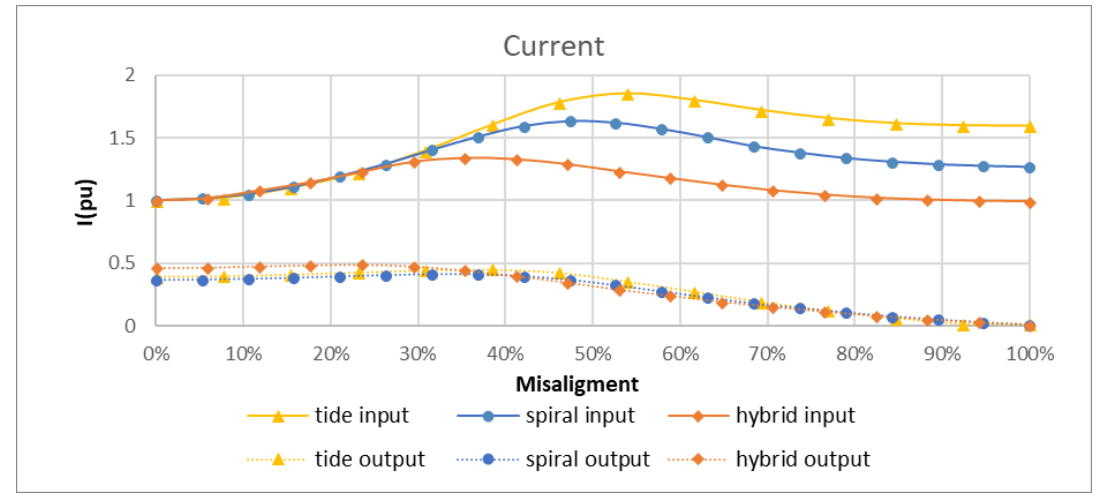

Figure 24. Measured current for primary compensation with resistive load.

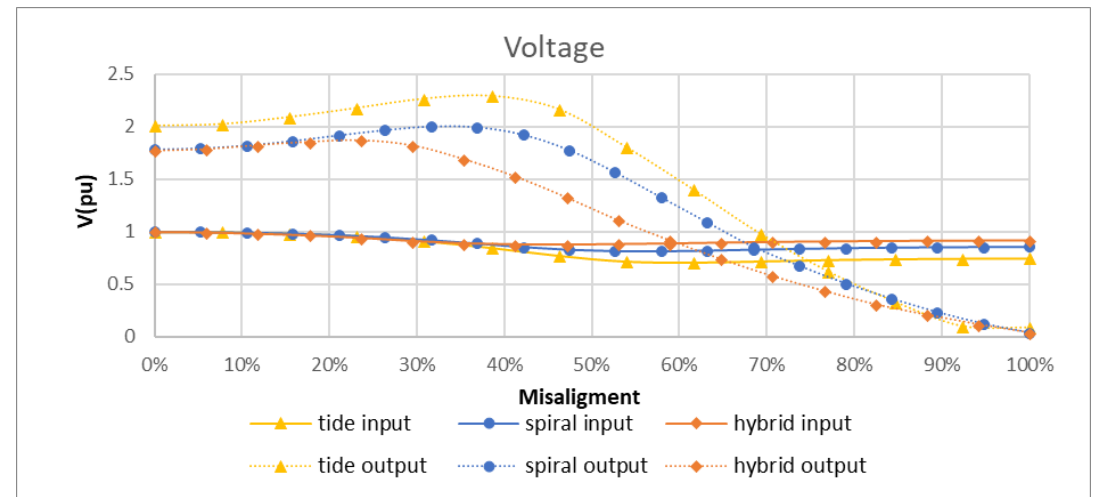

Figure 25. Measured voltage for primary compensation with resistive load. 


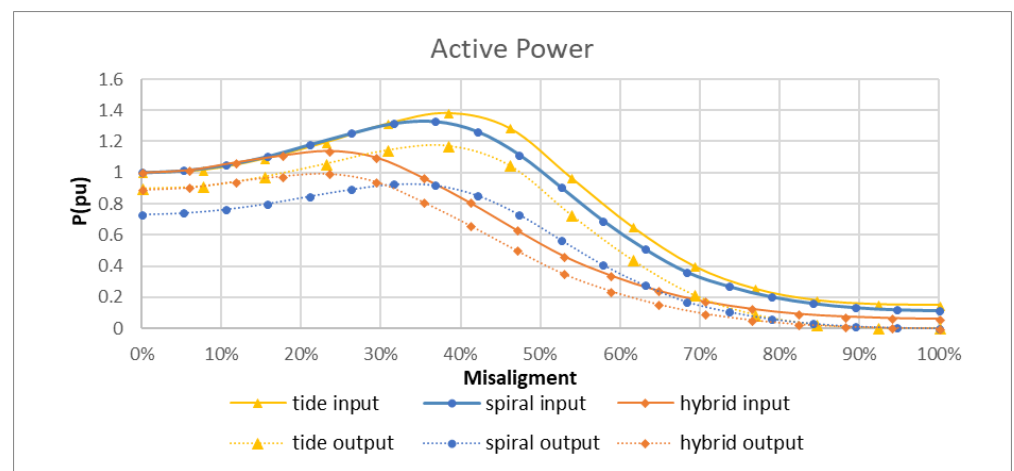

Figure 26. Measured active power for primary compensation with resistive load.

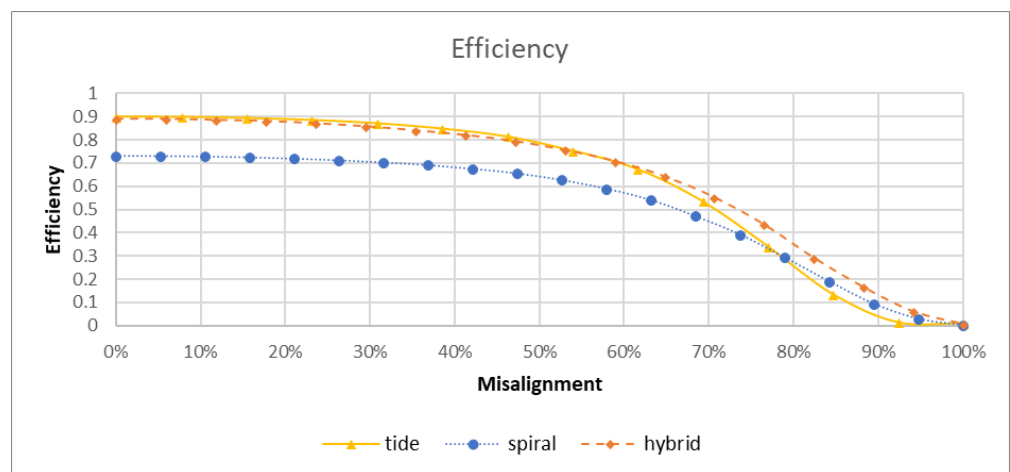

Figure 27. Measured efficiency for primary compensation with resistive load.

\section{Discussion}

The results are discussed in view of the aim of this work, which was to design a WPT transformer whose output electrical parameters are less sensitive to the effects of misalignment.

\subsection{Simulations}

\subsubsection{Graphs}

The simulation results of the current (see Figure 11) show that the input current was very similar among designs for misalignments smaller than $40 \%$, beyond which the current varied with the applied design. The tide coil and the hybrid intercore coil had similar values of the output current, with the latter having the largest value throughout the simulation. The current values for the spiral coil and the intercore coil were very similar and smaller than those of the other two designs.

For the voltage (see Figure 12), the input voltage was used as the reference value for the simulation calculations $(1 \mathrm{pu})$. The output voltage was very similar for the four designs tested.

The input active power (see Figure 13) results can be divided in two groups, the first group consisting of the tide coil and the spiral coil and the second group consisting of the intercore coil and the hybrid intercore coil. The first group had larger values compared to the second group as misalignment increased. For the output active power, the first group exhibited the same trends for all misalignments, starting from close to $0.4 \mathrm{pu}$ and decreasing smoothly to $0 \mathrm{pu}$. In the second group, the output active power for the aligned position for the hybrid intercore coil was $0.6 \mathrm{pu}$ and that for the intercore coil was $0.5 \mathrm{pu}$. The decreases in the output active power with increasing misalignment were similar for the two designs.

As shown in Figure 14, the efficiency followed the results of the output active power, showing that the hybrid intercore coil has the best efficiency when misalignment was considered. 
Contour and vector plots are shown for the secondary coil to illustrate the influence of the magnetic material layer on the primary side. The magnetic field strength contour plot (see Figure 15) shows that the tide coil and the spiral coil had similar distributions; this is attributed to these coils having the same magnetic material distribution (i.e., a layer below the primary coil).

The intercore coil and the hybrid intercore coil had a magnetic material between the coil turns. The utilization of a uniform distribution of the magnetic material did not affect the magnetic field strength when misalignment occurred. Moreover, when the magnetic material was used only in the inner part of the coil, the distribution of the magnetic field was greatly affected, reducing the maximum value when the coils were aligned, as can be observed for the hybrid intercore coil. Of note, the values of the magnetic field were stable as seen on the 4 first-alignment positions of the hybrid intercore coil presented in Figure 15.

\subsubsection{Visual Representation}

The vector representation in Figure 16 shows the magnetic vector potential. The magnetic vector potential can be used to calculate the mutual inductance of coils, which affects the electrical parameters of the WPT transformer.

For the tide coil, the magnetic vector potential is concentrated in the outer part of the coil. For the other designs, it is concentrated in the center part of the coils. The concentration decreased with increasing misalignment, as expected, 3 first-alignment positions. The spiral and intercore coils had very similar distributions, indicating that the magnetic material uniformly distributed between the coils did not affect the intensity of the magnetic vector potential when coil misalignment occurred.

For the hybrid intercore coil, the distribution of the magnetic material was not uniform; half of the coil had magnetic material between the turns and the other half had turns that were firmly wound. The effect can be seen in the results. There was a concentration of vectors in the area beyond where the magnetic material was installed increasing the density of vectors with larger values. As misalignment increased, the values decreased but the concentration of vectors with high values (represented by warmer colors in the figures) was the highest among the designs.

From the isometric view of the hybrid intercore coil in the aligned position and in the third intermediary misaligned position (see Figure 17), the vector potentials are perpendicular to the surface of the coil and the vector potentials (cones) are concentrated in the middle of the coil.

\subsubsection{Simulation Overview}

The simulations showed that the hybrid intercore coil had the best efficiency among the studied coil designs. However, the improvement is not clear since the values of the voltage and current are very similar to those for the other designs. The contour and vector plots showed a clear improvement in the magnetic field strength distribution and the concentration of the magnetic vector potential, showing that the utilization of a non-uniform distribution of a magnetic material between the coil turns could improve robustness against misalignment.

\subsection{Measurements}

Measurements were performed for two circuit configurations of the WPT, namely the pure resistive load and primary compensation with a resistive load.

\subsubsection{Pure Resistive Load}

Figures 18-23 show two sets of results, the first for the sine wave input (lines) and the second for the square wave input (marks). The input current (see Figure 18) shows that the change in the design or the input signal waveform did not affect the values of the electrical parameters. In Figure 19, the output current for the hybrid intercore coil had the larger values. For misalignment greater than $50 \%$, the values for the three designs were similar. The values obtained for the two types of waveform were the same for a given misalignment. 
The output voltage (see Figure 20) for the spiral coil was the largest, followed by those for the hybrid intercore and tide coils. Unlike for other parameters, the output voltage was different for the sine wave input and the square wave input, for which the values were slightly smaller. The trends of the input active power (see Figure 21) are similar to those of the output voltage, with the spiral coil having the largest values and the hybrid intercore coil having the smallest values. The tide and spiral models had slightly smaller values for the square wave than for the sine wave, whereas the hybrid intercore values were the same.

For the output active power (see Figure 22), the tide coil and the spiral coil had the largest and smallest values, respectively, for the tested misalignments. The hybrid intercore coil had values close to those for the tide coil at the aligned position and then its values decreased, becoming similar to those for the spiral coil, at a misalignment of $30 \%$. For the pure resistive load, the tide coil had the largest efficiency until a misalignment of around $80 \%$. The hybrid coil had slightly smaller values for a given misalignment; its efficiency increased beyond a misalignment of $80 \%$. For the spiral coil, the values of efficiency were smaller than those for the other two designs. For the sine wave input, but not the square wave input, its efficiency beyond a misalignment of $80 \%$ was largest among the designs.

\subsubsection{Primary Compensation with Resistive Load}

For primary compensation with a resistive load, only the square wave input was used. The input current (see Figure 24) increased with increasing misalignment; this was expected since the system was operating in resonance mode. With an increase in misalignment, the inductance of the coils changed and thus the compensation value required to maintain the system in resonance mode changed, making the system operate outside the resonance mode and thus generate an overcurrent. The tide coil had a maximum overcurrent of $1.8 \mathrm{pu}$, obtained at $55 \%$ misalignment. At total misalignment, the value of the current was about $1.55 \mathrm{pu}$. The spiral coil had a maximum overcurrent of $1.55 \mathrm{pu}$ for $45 \%$ misalignment and a current of 1.4 pu for total misalignment. For the hybrid intercore coil, there was an overcurrent, but the value was smaller than those for the other designs; it was $1.44 \mathrm{pu}$ at $35 \%$ misalignment. The input current decrease to 1 pu at total misalignment.

The output current values were very similar; they were $0.5 \mathrm{pu}$ until $40 \%$ misalignment, and then decreased to 0 at total misalignment.

Voltage is presented in Figure 25, the input voltage values were around 1 pu until $20 \%$ misalignment, and then started to decrease very slowly, stabilizing at $0.9 \mathrm{pu}$ at around $40 \%$ misalignment and at $0.8 \mathrm{pu}$ at $55 \%$ misalignment for the spiral and hybrid coils. The output voltage started at $2 \mathrm{pu}$ for the tide coil and reached a maximum of $2.4 \mathrm{pu}$ at around $38 \%$ misalignment; it then decreased steadily to 0 at total misalignment. The spiral coil had an output curve similar to that for the tide coil, but the values were slightly smaller, with an initial value of $1.8 \mathrm{pu}$ and a maximum value of 2 pu at $35 \%$ misalignment. The hybrid intercore coil did not exhibit an overvoltage; the value remained about 1.8 pu until $25 \%$ misalignment and then decreased to 0 at total misalignment.

The input active power (see Figure 26) graphs for the tide coil and the spiral coil have similar shapes; they start at $1 \mathrm{pu}$, increase to around $1.35 \mathrm{pu}$ at a misalignment of $35 \%$, and then decrease smoothly until around $85 \%$ misalignment, for which the value was around $0.1 \mathrm{pu}$. For the hybrid intercore coil, the input active power increased slightly to $1.1 \mathrm{pu}$ for a $25 \%$ misalignment and then decreased to around $0.1 \mathrm{pu}$ at total misalignment. The output active power for the three coils designs had shapes that followed the input, with decreased values representing losses in power transmission.

The efficiency (see Figure 27) of the tide coil and the hybrid intercore coil was the same until $60 \%$ misalignment, at which point the tide model decreased faster. The spiral coil had an efficiency at alignment of only $72 \%$. Its efficiency values were smaller than those for the tide coil until $75 \%$ misalignment, where it became bigger. 


\subsubsection{Measurement Overview}

The measurements showed that the type of wave (sine or square) for a pure resistive load did not affect the results. The tide coil was less affected by the flux losses; this was attributed to its smaller size. With the compensation setup, which made the system much closer to an actual WPT transformer in operation, the hybrid intercore coil had similar performance in terms of efficiency, and its input overcurrent and output overvoltage were drastically reduced. The constructive control maintained the operation in safer values for both inverter and load with no additional equipment or control design, maintaining the same WPT structure without moving parts.

\section{Conclusions}

This study proposed a novel design for a WPT transformer coil that utilizes a magnetic material between the coil turns to improve the robustness of the system against the effects of misalignment on the output electrical parameters. FEM simulations of the proposed coil structure were performed and showed that the magnetic field strength was more stable when misalignment occurred. The non-uniformity of the magnetic material increased the magnetic vector potential and diminished its reduction when misalignment occurred. Furthermore, the efficiency of the hybrid intercore coil was the highest among the studied designs.

On the other hand, when prototype coils were constructed the advantage of the utilization of intercore coil took place when the system was operated with a square wave and compensation circuit misalignment tended to generate input overcurrent and output overvoltage. Moreover, for the hybrid intercore coil, the overvalues were greatly decreased with no further external control.

In conclusion, the proposed design for the planar coil of a WPT transformer improves the magnetic and electrical characteristics when misalignment occurs without adding moving parts, external control, or additional systems.

For future work the authors will focus on the study of the optimization of the magnetic material layer thickness to maximize the robustness against misalignment. Another point that will be analyzed is the utilization of different winding designs on the secondary coil to enhance the achievements of the current work.

Author Contributions: Conceptualization, Joao Víctor Pinon Pereira Dias; Data curation, Joao Víctor Pinon Pereira Dias; Formal analysis, Joao Víctor Pinon Pereira Dias; Funding acquisition, Masafumi Miyatake; Methodology, Joao Víctor Pinon Pereira Dias; Supervision, Masafumi Miyatake; Writing—original draft, Joao Víctor Pinon Pereira Dias; Writing — review \& editing, Masafumi Miyatake.

Funding: This research received no external funding.

Acknowledgments: This work was carried out with the support of the Coordination for the Improvement of Higher Level Personnel (Capes)—Brazil.

Conflicts of Interest: The authors declare no conflict of interest.

\section{Nomenclature}

$\vec{A} \quad$ Magnetic vector potential

ATO Automatic train operation

CAD Computer-aided design

d Lateral misalignment

$d_{1}, d_{2} \quad$ Distance from the primary substrate to the primary winding and secondary winding

$d_{1}^{\prime}, d_{2}^{\prime} \quad$ Distance from the secondary substrate to the primary winding and secondary winding

$E(k) \quad$ Elliptical integral of the second kind

FEM Finite element method

$h_{1}, h_{2} \quad$ Winding heights in the axial direction for primary winding and secondary winding

J Current density

$J_{0}, J_{1} \quad$ Bessel function of the first kind 


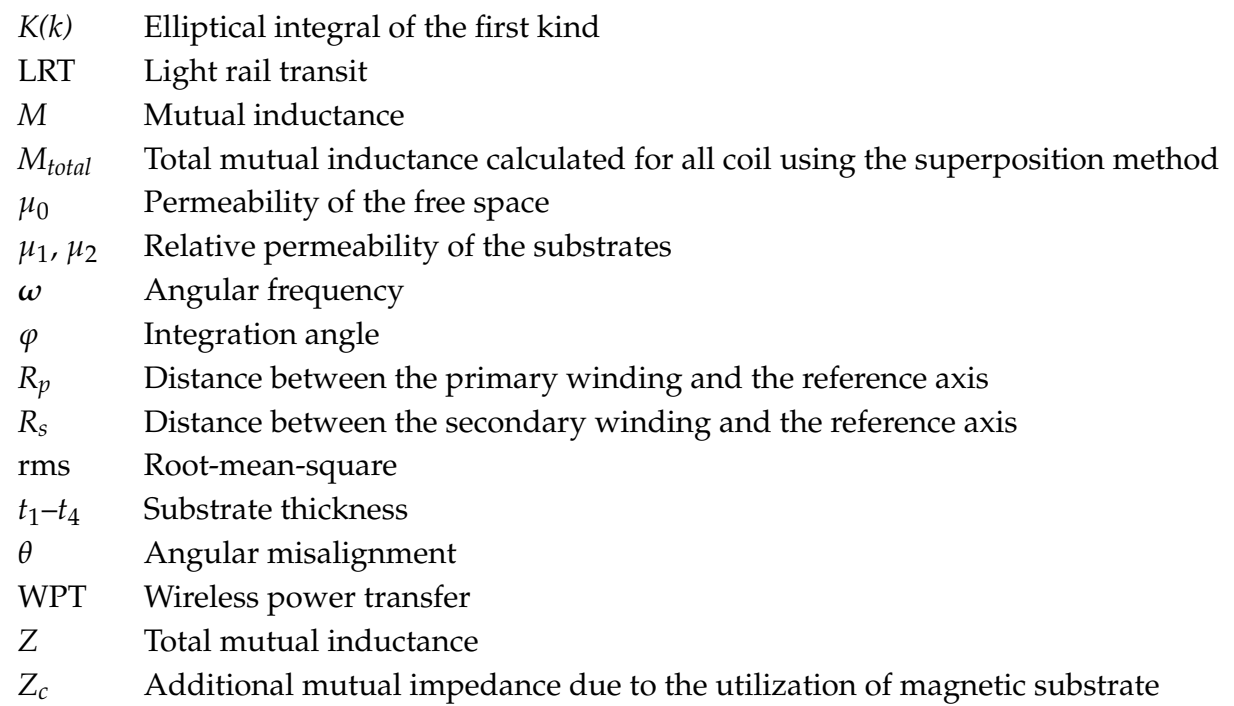

\section{References}

1. Vltcarioca Home Page. Available online: http://www.vltcarioca.rio (accessed on 18 May 2018).

2. Kaemppert, W. A Popular History of American Invention; C. Scribner's Sons: New York, NY, USA, 1924; pp. 106-133.

3. Electric Transport in Latin America Home Page. Available online: http://www.tramz.com/br/cp/cp/html (accessed on 18 May 2018).

4. Yarra Trams Home Page. Available online: http:/ / www.yarratrams.com.au (accessed on 18 May 2018).

5. Dart Home Page. Available online: http://www.dart.org (accessed on 18 May 2018).

6. Ratp Home Page. Available online: http://www.ratp.fr/en (accessed on 18 May 2018).

7. Bomsinal Home Page. Available online: http:/ /www.bomsinal.com (accessed on 18 May 2018).

8. TTC Home Page. Available online: http://www.ttc.ca (accessed on 18 May 2018).

9. Land Transport Authority Home Page. Available online: http://www.lta.gov.sg (accessed on 18 May 2018).

10. Tbm Home Page. Available online: http://www.infotbm.com/en (accessed on 18 May 2018).

11. Caf Home Page. Available online: http://www.caf.net/en/ecocaf/nuevas-soluciones/tranvia-greentech. php (accessed on 18 May 2018).

12. Becker, F.; Dämmig, A. Catenary free operation of light rail vehicles-Topology and operational concept. In Proceedings of the 2016 18th European Conference on Power Electronics and Applications (EPE'16 ECCE Europe), Karlsruhe, Germany, 5-9 September 2016. [CrossRef]

13. Rail Journal Home Page. Available online: http://www.railjournal.com/index.php/asia/battery-electrictrains-for-japans-oga-line.html (accessed on 18 May 2018).

14. Primove Home Page. Available online: http://www.primove.bombardier.com/applications/tram.html (accessed on 18 May 2018).

15. Ukita, K.; Kashiwagi, T.; Sakamoto, Y.; Sasakawa, T. Evaluation of a non-contact power supply system with a figure-of-eight coil for railway vehicles. In Proceedings of the 2015 IEEE PELS Workshop on Emerging Technologies: Wireless Power (2015 WoW), Daejeon, Korea, 5-6 June 2015. [CrossRef]

16. Cho, D.; Jung, G.; Yoon, U.; Lee, B. Development \& Implementation of Electric Tram System with Wireless Charging Technology. ICT Express 2015, 1, 34-38. [CrossRef]

17. Lee, S.H.; Lorenz, R.D. Development and Validation of Model for 95\%-Efficiency 220-W Wireless Power Transfer Over a 30-cm Air Gap. IEEE Trans. Ind. Appl. 2011, 47, 2495-2504. [CrossRef]

18. Li, Y.; Mai, R.; Lin, T.; Sun, H.; He, Z. A Novel WPT System Based on Dual Transmitters and Dual Receivers for High Power Applications: Analysis, Design and Implementation. Energies 2017, 10. [CrossRef]

19. Mude, K.N.; Bertoluzzo, M.; Buja, G.; Pinto, R. Design and experimentation of two-coil coupling for electric city-car WPT charging. J. Electromagn. Waves Appl. 2016, 30, 70-88. [CrossRef] 
20. Yamamoto, K.; Maruyama, T.; Kondo, K.; Kashiwagi, T. A Study on the circuit configuration with capacitors to compensate the power factor for high-power contactless power transformer. In Proceedings of the 2013 International Conference on Electrical Machines and Systems (ICEMS), Busan, Korea, 26-29 October 2013; pp. 2233-2238.

21. Dias, J.V.P.P.; Miyatake, M. Misalignment based electric circuit of a wireless power transfer transformer for light rail transit. In Proceedings of the 2017 20th International Conference on Electrical Machines and Systems (ICEMS), Sydney, NSW, Australia, 11-14 August 2017. [CrossRef]

22. Luo, S.; Takada, Y.; Koseki, T. Experimental Verification of Sensor-less Coil Position Control System and its Gap Deviation Tolerance Improvement Method in Wireless Power Transmission System of Electrical Trains (自動車 交通・電気鉄道合同研究会 鉄道一般,エネルギーストレージシステムの応用). 電気学会研究会資料 VT 2015, 2015, 19-24.

23. Hwang, K.; Cho, J.; Kim, D.; Park, J.; Kwon, H.J.; Kwak, I.S.; Park, H.H.; Ahn, S. An Autonomous Coil Alignment System for the Dynamic Wireless Charging of Electric Vehicles to Minimize Lateral Misalignment. Energies 2017, 10. [CrossRef]

24. Villa, J.L.; Sallán, J.; Llombart, A.; Sanz, J.F. Design of a high frequency Inductively Coupled Power Transfer system for electric vehicle battery charge. Appl. Energy 2009, 86, 355-363. [CrossRef]

25. Steinmetz, C.P. Theory and Calculation of Alternating Current Phenomena, 1st ed.; Electrical World and Engineer, Inc.: New York, NY, USA, 1900; pp. 195-236. Available online: https://archive.org/details/ theorycalculatio00steiiala (accessed on 15 May 2018).

26. Maxwell, J. A Treatise on Electricity and Magnetism, 3rd ed.; Dover Publications Inc.: New York, NY, USA, 1954; pp. 138-222. Available online: https://archive.org/details/ATreatiseOnElectricityMagnetism-Volume2 (accessed on 15 May 2018).

27. Anele, A.O.; Hamam, Y.; Chassagne, L.; Linares, J.; Alayli, Y.; Djouani, K. Computation of the Mutual Inductance between Air-Cored Coils of Wireless Power Transformer. J. Phys. Conf. Ser. 2015, 633. [CrossRef]

28. Su, Y.P.; Liu, X.; Hui, S.Y.R. Mutual Inductance Calculation of Movable Planar Coils on Parallel Surfaces. IEEE Trans. Power Electron. 2009, 24, 1115-1123. [CrossRef]

29. Luo, Z.; Wei, X. Analysis of Square and Circular Planar Spiral Coils in Wireless Power Transfer System for Electric Vehicles. IEEE Trans. Ind. Electron. 2018, 65, 331-341. [CrossRef]

30. Valtchev, S.; Borges, B.; Brandisky, K.; Klaassens, J.B. Resonant Contactless Energy Transfer with Improved Efficiency. IEEE Trans. Power Electron. 2009, 24, 685-699. [CrossRef]

31. Dias, J.V.P.P.; Kim, H.; Jang, D. Computer model for railway inductive power supply using Valtchev model. In Proceedings of the 2011 International Conference on Electrical Machines and Systems, Beijing, China, 20-23 August 2011. [CrossRef]

32. Hurley, W.G.; Duffy, M.C. Calculation of self and mutual impedances in planar magnetic structures. IEEE Trans. Magn. 1995, 31, 2416-2422. [CrossRef]

33. Wilcox, D.J.; Hurley, W.G.; Conlon, M. Calculation of self and mutual impedances between sections of transformer windings. IEE Proc. C-Gener. Transm. Distrib. 1989, 136, 308-314. [CrossRef]

34. Hurley, W.G.; Duffy, M.C. Calculation of self- and mutual impedances in planar sandwich inductors. IEEE Trans. Magn. 1997, 33, 2282-2290. [CrossRef]

35. Liu, X.; Hui, S.Y. Optimal Design of a Hybrid Winding Structure for Planar Contactless Battery Charging Platform. IEEE Trans. Power Electron. 2008, 23, 455-463. [CrossRef]

36. Hurley, W.G.; Duffy, M.C.; Zhang, J.; Lope, I.; Kunz, B.; Wölfle, W.H. A Unified Approach to the Calculation of Self- and Mutual-Inductance for Coaxial Coils in Air. IEEE Trans. Power Electron. 2015, 30, 6155-6162. [CrossRef]

37. Dias, J.V.P.P.; Miyatake, M. Improved core shape of contacless transformer for LRT system. In Proceedings of the 2015 International Conference on Electrical Systems for Aircraft, Railway, Ship Propulsion and Road Vehicles (ESARS), Aachen, Germany, 3-5 March 2015. [CrossRef]

38. Tan, L.; Li, J.; Chen, C.; Yan, C.; Guo, J.; Huang, X. Analysis and Performance Improvement of WPT Systems in the Environment of Single Non-Ferromagnetic Metal Plates. Energies 2016, 9. [CrossRef]

39. Wen, F.; Huang, X. Optimal Magnetic Field Shielding Method by Metallic Sheets in Wireless Power Transfer System. Energies 2016, 9. [CrossRef]

40. Toshiba. Available online: http://www.toshiba-tmat.co.jp/en/res/theme4.htm (accessed on 18 May 2018). 
41. Kazimierczuk, M.K. High-Frequency Magnetic Components, 1st ed.; John Wiley \& Sons: Chichester, UK, 2009; pp. 412-470.

42. JMAG Home Page. Available online: http:/ /www.jmag-international.com (accessed on 18 May 2018).

(c)

(C) 2018 by the authors. Licensee MDPI, Basel, Switzerland. This article is an open access article distributed under the terms and conditions of the Creative Commons Attribution (CC BY) license (http://creativecommons.org/licenses/by/4.0/). 